\title{
Real-world evaluation of compliance and preference in Alzheimer's disease treatment
}

This article was published in the following Dove Press journal:

Clinical Interventions in Aging

3 November 2015

Number of times this article has been viewed

\author{
Ming-Chyi Pai ${ }^{1,2}$ \\ Hany Aref ${ }^{3}$ \\ Nazem Bassil ${ }^{4}$ \\ Nagaendran Kandiah ${ }^{5}$ \\ Jae-Hong Lee ${ }^{6}$ \\ AV Srinivasan ${ }^{7}$ \\ Shelley diTommaso ${ }^{8}$ \\ Ozgur Yuksel ${ }^{8}$ \\ 'Division of Behavioral Neurology, \\ Department of Neurology, \\ ${ }^{2}$ Alzheimer's Disease Research Center. \\ National Cheng Kung University \\ Hospital, College of Medicine, \\ National Cheng Kung University, \\ Tainan City, Taiwan; ${ }^{3}$ Department \\ of Neurology, Ain Shams University, \\ Cairo, Egypt; ${ }^{4}$ Saint Georges Hospital \\ Medical Center, Balamand University, \\ Beirut, Lebanon; ${ }^{5}$ Department of \\ Neurology, National Neuroscience \\ Institute, Tan Tock Seng Hospital, \\ Singapore; 'Department of Neurology, \\ Asan Medical Center, University of \\ Ulsan College of Medicine, Songpa-gu, \\ Seoul, South Korea; ${ }^{7}$ The Tamil Nadu \\ Dr MGR Medical University, Chennai, \\ Tamil Nadu, India; ${ }^{8}$ Novartis Pharma
}

AG, Postfach, Basel, Switzerland

\begin{abstract}
Purpose: Rivastigmine transdermal patch has shown higher caregiver satisfaction and greater preference than oral formulation in patients with Alzheimer's disease. However, there is limited literature available related to caregiver preference or treatment compliance in real-world clinical settings. To date, no such data are available from Asia and the Middle East, which account for a sizeable proportion of patients with Alzheimer's disease. The objective of this study was to evaluate treatment preference and compliance with oral and transdermal medications in daily clinical practice in an ethnically diverse patient population from Asia and the Middle East with mild-to-moderate Alzheimer's disease.
\end{abstract}

Patients and methods: RECAP (Real-world Evaluation of Compliance And Preference in the treatment of Alzheimer's disease) was a 24-week, multicenter, prospective, noninterventional study. Two treatment cohorts were observed during the study: oral (cholinesterase inhibitors or memantine) and transdermal (rivastigmine patch). Caregiver preference, physician preference, and patient compliance were evaluated at week 24 .

Results: A total of 978 of 1,931 enrolled patients (mean age: 72.8 years; $50.5 \%$ female) were in the transdermal cohort. For patients with exposure to both oral and transdermal monotherapy $(\mathrm{n}=330)$, a significant caregivers' preference for the transdermal monotherapy was observed $(82.7 \% ; P<0.0001)$. Of the 89 participating physicians, 71 indicated preference for transdermal monotherapy. Patient compliance was also significantly higher for transdermal than oral monotherapy $(P<0.0001)$.

Conclusion: Our study showed higher caregiver and physician preference and greater patient compliance with transdermal monotherapy in daily practice.

Keywords: rivastigmine, Alzheimer's disease, cholinesterase inhibitors, patient compliance, observational study, transdermal patch

\section{Introduction}

Alzheimer's disease (AD), a progressive neurodegenerative disorder, accounts for up to $75 \%$ of all dementia cases. ${ }^{1}$ Worldwide, more than 35 million people live with $\mathrm{AD}$, and this number is expected to double by 2030 and reach 115 million by $2050 .^{2}$ The progression of symptoms in patients with $\mathrm{AD}$ can be delayed by early and aggressive treatment management; ${ }^{3,4}$ however, patient compliance to treatment remains a challenge. ${ }^{5}$ As the disease progresses, patients with $\mathrm{AD}$ require increased assistance from their caregivers. Caregivers, especially family members, play a key role in the care and treatment compliance of patients with $\mathrm{AD} .5,6$

The currently approved oral symptomatic treatments for $\mathrm{AD}$ are donepezil, galantamine, rivastigmine (cholinesterase inhibitors), and memantine ( $N$-methyl-D-aspartate receptor antagonist). ${ }^{7}$ Rivastigmine is also available as a transdermal formulation that provides continuous delivery over 24 hours and results in fewer side effects compared with oral rivastigmine. ${ }^{8,9}$ The efficacy and safety of the rivastigmine transdermal formulation 
have been demonstrated in various randomized controlled trials. ${ }^{10-13}$ However, there is limited literature available on the caregiver and physician treatment preference and patient compliance with transdermal rivastigmine in a real-world clinical setting. ${ }^{14-17}$ To date, no such study is available in patients from Asia and the Middle East, despite this part of the world accounting for a sizeable proportion of patients with AD.

The present study was designed to evaluate the treatment preference and compliance in an ethnically diverse population from Asia and the Middle East with mild-to-moderate AD treated with oral (cholinesterase inhibitors or memantine) or transdermal monotherapy (rivastigmine patch) in a real-world clinical setting. Patients in this study were treated according to the usual care and not by the protocol. This study reports "real-world" evidence. The real world characterizes the fact that data collected in this study originated from the routine medical care of patients.

\section{Patients and methods}

\section{Study design}

RECAP (Real-world Evaluation of Compliance And Preference in the treatment of Alzheimer's disease) was a 24-week, multicenter, prospective, noninterventional study conducted at 92 participating sites in India (24 sites), Egypt (34 sites), South Korea (15 sites), Taiwan (9 sites), Lebanon (8 sites), and Singapore (2 sites) between March 2011 and July 2013 (Figure 1). Patients were invited to participate as they were prescribed a capsule or a transdermal patch therapy by their treating physician for AD. The patients participated in this study after providing written informed consent, or where applicable, such consent provided by a legally acceptable representative of the patient. The eligible patients were grouped into one of the two treatment cohorts according to the route of administration of the AD medication taken at the study entry: oral (donepezil, galantamine, rivastigmine, or memantine) or

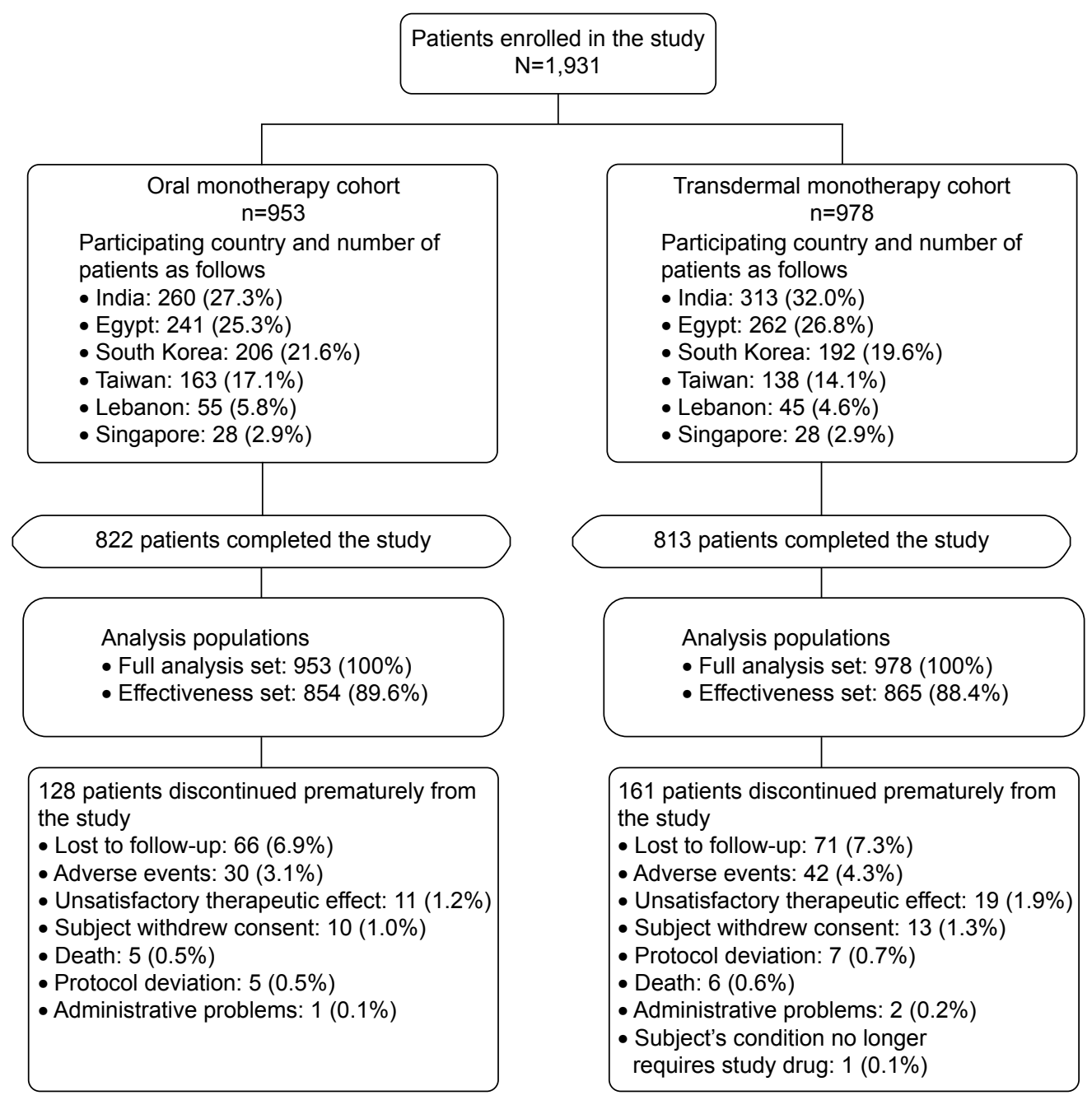

Figure I Patient disposition.

Notes: A patient having completed visits up to visit 3 (week 24) was considered having completed the study. 
transdermal (rivastigmine). The observational period for each participant was 24 weeks ( \pm 8 weeks). Data were collected at three time points: study entry (baseline), week 12 ( \pm 4 weeks), and week 24 ( \pm 8 weeks; end of the study).

Aligning with the definition of noninterventional study (Article 2[c] EU Directive 2001/20/EC), ${ }^{18}$ the medications under observation were prescribed in compliance with the marketing authorization, and the treatment decision was made as part of patients' usual medical care and before study participation. No diagnostic or monitoring procedures, in addition to usual care, were performed. Study participation included completion of the Caregiver Medication Questionnaire (CMQ) at the end of the study. The CMQ included questions derived from AD Caregiver Preference Questionnaire (ADCPQ) that was psychometrically validated using data from the IDEAL (Investigation of transDermal Exelon in ALzheimer's disease) study. ${ }^{13,19,20}$

The study was approved by the institutional review board, independent ethics committee, or research ethics board of each of the 92 sites and was conducted in accordance with the applicable guidelines and ethical principles of the Declaration of Helsinki. ${ }^{21,22}$ Informed consent was obtained before the data were collected. The patients were free to withdraw their consent to participate in the study at any stage.

\section{Study participants}

Male and female patients with mild-to-moderate AD who were at least 50 years of age were included in the study. Furthermore, patients were included in the study if they were prescribed oral or transdermal monotherapy (cholinesterase inhibitors or memantine) in adherence with the local prescribing information (ie, locally approved product label) and having a caregiver willing and able to answer the CMQ. Patients were excluded if contraindicated as per the local prescribing information/summary of product characteristics.

\section{Study objectives and assessments}

The primary objectives included evaluation of caregivers' preference and caregivers' assessment of patient compliance, using the CMQ at the end of the study. The CMQ included questions on patient compliance and satisfaction with treatment, general preference (oral versus transdermal treatment), and top three reasons for treatment preference. The caregivers indicated their preference by comparing their experience with the current medication form used during the study with a hypothetical situation where their patient could have received the medication in the alternative form. The patient's compliance for the current medication was rated on an 11-point scale $(0=$ "Never took the medication as prescribed" up to a maximum of $10=$ "Always took the medication as prescribed").

The secondary objectives assessed at the end of the study were to describe the concomitant use of psychotropic medication (yes/no) and the number of psychotropic medications used $(1,2,3$, or $>3)$ per patient, to assess physicians' preference for the oral or patch medication (including top three reasons for preference), and to evaluate the drug regimen among patients on cholinesterase inhibitors and memantine (the total daily dosage reached). Physicians' preference for treatment was assessed using a short physician's preference assessment questionnaire. The total scores for the MiniMental State Examination (MMSE) at the baseline and the end of the study were also recorded. The safety assessments included recording of frequency of adverse events (AEs) and discontinuations of treatment.

\section{Sample size and data analysis}

Sample size was based on practical considerations rather than on statistical. The sample-size calculation was based on precision (in terms of width of the two-sided $95 \%$ confidence interval), assuming a preference rate for transdermal patches of $60 \%$ and $70 \%$, and this assumption was based on the IDEAL study. ${ }^{13,19}$

This study was conducted as individual studies in six countries (India, Egypt, South Korea, Taiwan, Lebanon, and Singapore), and the data from all countries were pooled and analyzed. The full analysis set consisted of all patients who provided informed consent and received at least one dose of the medication under observation in this study. The effectiveness set excluded patients without any postbaseline effectiveness assessment. In addition, the effectiveness data collected after the time of treatment switch were excluded for any patient who switched the treatment cohort during the study. The effectiveness analyses were conducted on the effectiveness set, and all other analyses were conducted on the full analysis set. Descriptive statistics was used to present demographics and other baseline characteristics. Summary statistics for continuous variables included the number of observations (n), arithmetic mean, standard deviation (SD), minimum observations, lower quartile, median, upper quartile, and maximum observations. Categorical variables were presented with absolute and relative frequencies. A two-sided $95 \%$ confidence interval as well as $P$-values were presented for the caregivers' preferences and overall compliance rating for oral or transdermal patch. The 95\% confidence intervals were calculated as exact binomial 
confidence intervals. The analysis of covariance was used to show significant differences in patient compliance depending on the use of the oral or patch medication at the end of the study. Statistical significance on the two-sided significance level was set at $P<0.05$. All statistical analyses were performed using SAS statistical package version 9.2 (SAS Institute Inc., Cary, NC, USA).

\section{Results}

\section{Patient population and disposition}

Of the 1,931 patients enrolled, 953 (49.4\%) were in the oral monotherapy cohort and $978(50.6 \%)$ were in the transdermal monotherapy cohort. Overall, 1,635 (84.7\%) patients completed the study (oral monotherapy: 822 and transdermal monotherapy: 813; Figure 1). The baseline and demographic characteristics were comparable between the two treatment cohorts (Table 1). In the total study population, the mean (SD) age was 72.8 (8.34) years. Female sex is a known risk factor for $\mathrm{AD}$ in part due to the fact that women live longer; however, we observed a lower percentage of female patients $(50.5 \%)$ in the present noninterventional study compared with other studies. ${ }^{23-25}$ The majority of patients were of Asian ethnicity $(1,327,68.7 \%)$. The mean (SD) duration of AD was 0.9 (1.42) years and a total of $12.8 \%$ of patients had a family history of AD, specifically, $11.6 \%$ had a parent or sibling with AD. The most commonly reported psychiatric disorders at baseline were depression $(599,31.0 \%)$, insomnia (492, 25.5\%), anxiety $(476,24.7 \%)$, sleep disorder $(421,21.8 \%)$, agitation (368, 19.1\%), delusion (287, 14.9\%), and neurosis (124, 6.4\%). Overall, there were $518(26.8 \%)$ patients who experienced any

Table I Patient demographics and baseline characteristics

\begin{tabular}{|c|c|c|c|}
\hline & $\begin{array}{l}\text { Oral monotherapy } \\
\text { cohort, } n=953\end{array}$ & $\begin{array}{l}\text { Transdermal monotherapy } \\
\text { cohort, } n=978\end{array}$ & Total, $\mathbf{N}=\mathbf{I , 9 3}$ I \\
\hline Age, years ${ }^{a}$ & $72.6(8.45)$ & $72.9(8.24)$ & $72.8(8.34)$ \\
\hline \multicolumn{4}{|l|}{ Sex, n (\%) } \\
\hline Male & $470(49.3)$ & $485(49.6)$ & $955(49.5)$ \\
\hline Female & $483(50.7)$ & $493(50.4)$ & $976(50.5)$ \\
\hline \multicolumn{4}{|l|}{ Race, $n(\%)^{b}$} \\
\hline Caucasian & $262(27.5)$ & $260(26.6)$ & $522(27.0)$ \\
\hline Asian & $656(68.8)$ & $671(68.6)$ & I,327 (68.7) \\
\hline Others & $34(3.6)$ & $47(4.8)$ & $81(4.2)$ \\
\hline Patient's formal education, years & $8.7(6.02)$ & $9.1(5.92)$ & $8.9(5.97)$ \\
\hline Duration of $A D$, years & $0.9(1.53)$ & $0.8(1.30)$ & $0.9(\mathrm{I} .42)$ \\
\hline \multicolumn{4}{|l|}{ Prior treatment for $\mathrm{AD}^{c}$} \\
\hline Drug therapy & $209(21.9)$ & $309(31.6)$ & $518(26.8)$ \\
\hline No drug therapy & $744(78.1)$ & $668(68.3)$ & $\mathrm{I}, 412(73.1)$ \\
\hline \multicolumn{4}{|l|}{ Prior psychotropic concomitant medication ${ }^{d}$} \\
\hline Yes & $246(25.8)$ & $264(27.0)$ & $510(26.4)$ \\
\hline No & $706(74.1)$ & $710(72.6)$ & $\mathrm{I}, 416(73.3)$ \\
\hline \multicolumn{4}{|l|}{ Any family history of $A D^{e}$} \\
\hline Yes & $132(13.9)$ & $115(11.8)$ & $247(12.8)$ \\
\hline No & $820(86.0)$ & $862(88.1)$ & I,682 (87.I) \\
\hline \multicolumn{4}{|l|}{ Current smoker ${ }^{f}$} \\
\hline Yes & $92(9.7)$ & $104(10.6)$ & $196(10.2)$ \\
\hline No & $860(90.2)$ & $873(89.3)$ & $\mathrm{I}, 733(89.7)$ \\
\hline \multicolumn{4}{|l|}{ Alcohol history } \\
\hline Less than I drink per dayg & 904 (94.9) & $934(95.5)$ & I,838 (95.2) \\
\hline $\mathrm{I}-2$ drinks per day & $38(4.0)$ & $37(3.8)$ & $75(3.9)$ \\
\hline 3 or more drinks per day & $10(1.0)$ & $6(0.6)$ & $16(0.8)$ \\
\hline \multicolumn{4}{|l|}{ Current living situation, $\mathrm{n}(\%)^{\mathrm{h}}$} \\
\hline Living alone & $49(5.1)$ & $51(5.2)$ & $100(5.2)$ \\
\hline Living with caregiver or other individual & $879(92.2)$ & $892(91.2)$ & I,77I (9I.7) \\
\hline Assisted living/group home & $24(2.5)$ & $34(3.5)$ & $58(3.0)$ \\
\hline MMSE & $17.8(4.70)$ & $17.7(4.67)$ & $17.8(4.68)$ \\
\hline
\end{tabular}

Notes: anformation about age was missing for one patient in the oral monotherapy cohort. 'Information about race was missing for one patient in the oral monotherapy cohort. Information about any prior treatment for AD was missing for two patients (one in each cohort). Information about any prior treatment for AD with psychotropic medication was missing for one patient in the oral monotherapy cohort and four patients in the transdermal monotherapy cohort. ${ }^{e}$ Family history of AD was missing for two patients (one in each cohort). flnformation about current smoker was missing for two patients (one in each cohort). ${ }^{8} \mathrm{Alcohol}$ history was missing for two patients (one in each cohort). "Information about current living situation was missing for two patients (one in each cohort). Data are shown as mean (SD), unless otherwise stated. Abbreviations: AD, Alzheimer's disease; MMSE, Mini-Mental State Examination; SD, standard deviation. 
treatment for $\mathrm{AD}$ prior to start of the study, and the proportion of patients who had AD therapy were comparable between the two treatment cohorts (oral: $21.9 \%$ and transdermal: $31.6 \%$ ). The mean (SD) MMSE scores at baseline were 17.8 (4.70) and 17.7 (4.67) in the oral and transdermal monotherapy cohorts, respectively. Most patients enrolled in the study $(1,771,91.7 \%)$ were living with a caregiver or other individuals.

\section{Primary assessments}

For patients with exposure only to either the oral or transdermal monotherapy, the caregivers' preference at week 24 was significantly in favor of the treatment to which the patient was exposed ( $P<0.0001$ for both cohorts). However, the caregivers of patients who were exposed to both forms of therapies demonstrated a higher preference for the transdermal monotherapy compared with the oral monotherapy $(P<0.0001$; Figure 2). Patient compliance was significantly higher in the transdermal monotherapy cohort than the oral monotherapy cohort $(P<0.0001$; Figure 3$)$, and there was a numerically greater proportion of patients who "always took the medication as prescribed" in the transdermal monotherapy cohort according to caregivers' assessments $(28.6 \%$ versus $24.9 \%$, respectively) at week 24 .

\section{Secondary assessments}

In the total study population, there were $22.9 \%, 14.3 \%$, $5.4 \%$, and $3.6 \%$ of patients who took one, two, three, and more than three psychotropic medications, respectively. Furthermore, the use of concomitant psychotropic medication and the number of different psychotropic medications per patient were comparable between the two treatment cohorts.

There was a higher physician preference for transdermal monotherapy. Of the 89 participating physicians, most indicated preference for transdermal (79.8\%) over oral $(20.2 \%)$ monotherapy at the end of the study. The reasons ranked by physicians preferring patch medication as most important (preference rank 1) were "easier to use" (33.8\%) followed by "easier to comply" (19.7\%) and "easier to administer" (18.3\%; Figure 4); and the most important reasons (preference rank 1) for physicians to prefer oral medication was "easier to comply/better acceptance by the patient" (44.4\%) followed by "easier to use" $(22.2 \%)$ and "easier to administer" (16.7\%).

Overall, more patients $(60.5 \%)$ on memantine reached the highest therapeutic dose compared with patients on oral and transdermal cholinesterase inhibitors. A greater percentage $(49.6 \%)$ of patients treated with transdermal rivastigmine reached the highest therapeutic dose compared with patients treated with oral cholinesterase inhibitors including oral rivastigmine (Figure 5).

The change in the MMSE scores from baseline to the end of the study was obtained from a total of $1,301(76 \%)$ patients in the effectiveness set. The mean (SD) MMSE

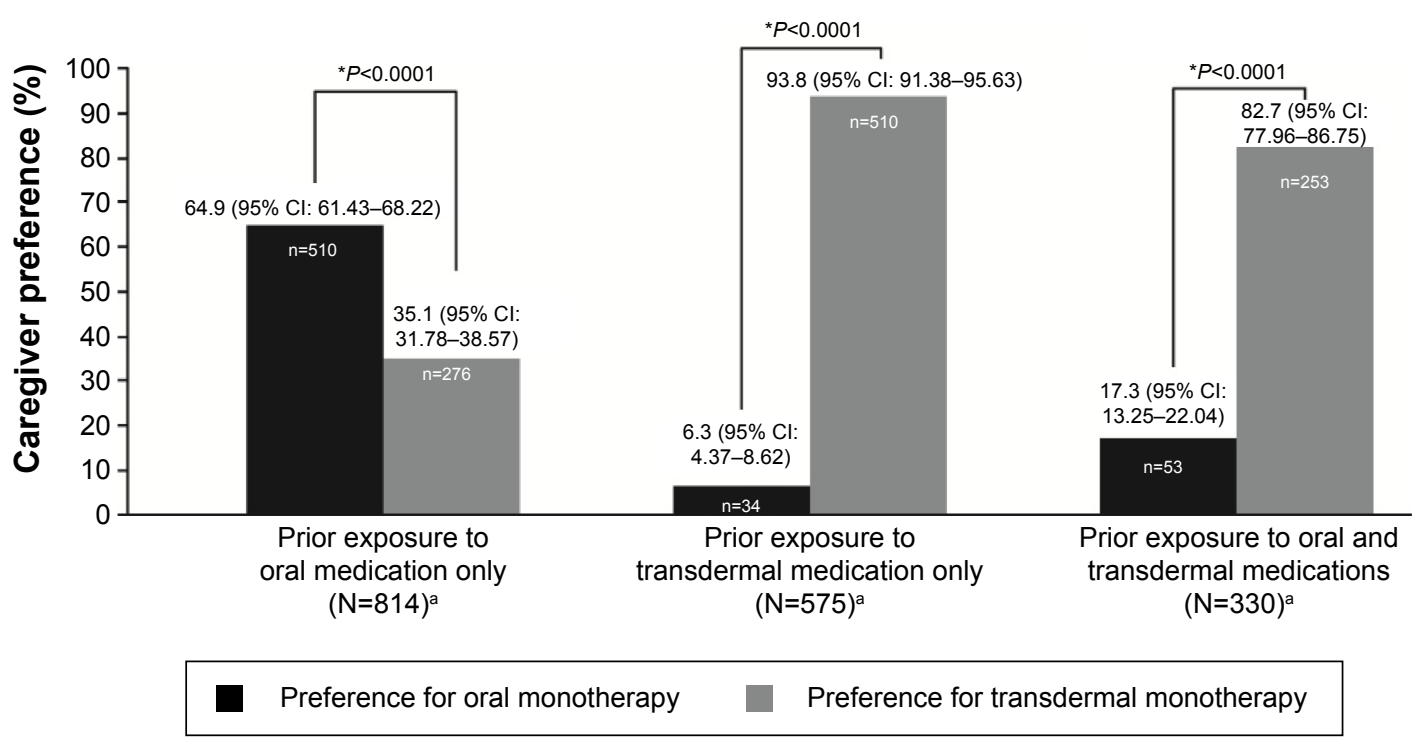

Figure 2 Caregiver preference for oral or transdermal medication at the end of the study, by prior exposure.

Notes: *A $P$-value of $<0.05$ indicates a statistically significant difference in proportions between the two cohorts. $P$-value is based on a binomial test statistic to compare two proportions. The $95 \% \mathrm{Cls}$ were calculated as exact binomial Cls. Exposed to oral and transdermal patch medication, of the 308 questionnaires, two were answered

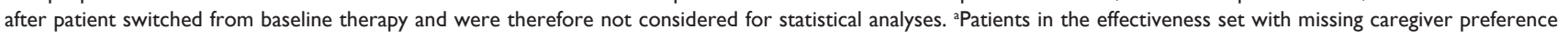
assessment were not included in the calculations.

Abbreviation: $\mathrm{Cl}$, confidence interval. 


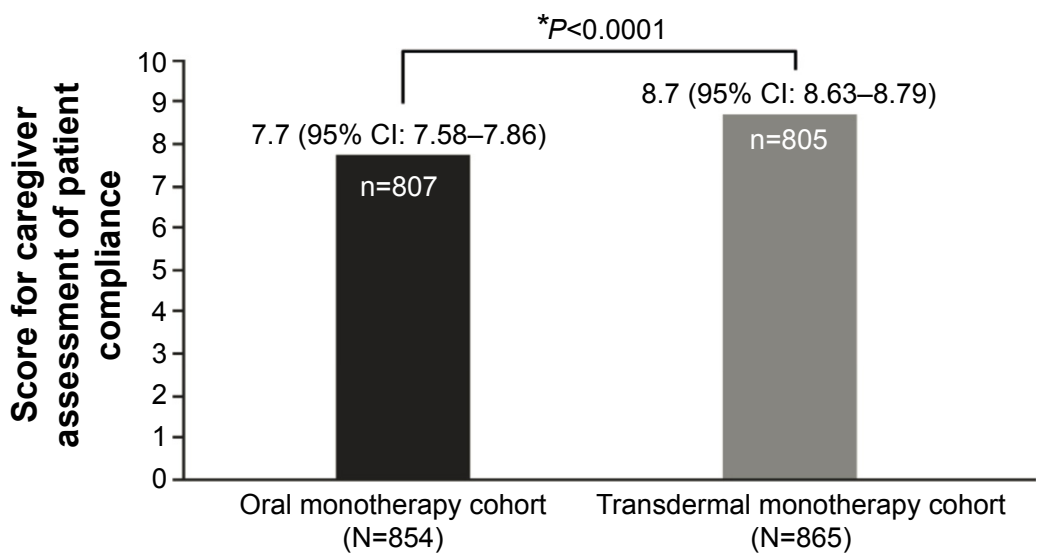

Figure 3 Caregiver assessment of patient compliance to treatment at the end of the study.

Notes: *A P-value of $<0.05$ indicates a statistically significant difference in the mean scores between the two cohorts. $P$-value is based on Student's $t$-test statistic to compare two means. A two-sided 95\% confidence interval for the mean score for oral and transdermal monotherapy cohorts based on Student's t-test statistic. Patient compliance rated on an II-point scale from $0=$ "Never took the medication as prescribed" up to a maximum of $10=$ "Always took the medication as prescribed" using the Caregiver Medication Questionnaire. Patients in the effectiveness set with missing assessment of compliance were not included in the calculations. Compliance was assessed at the end of the study. The end of the study was at visit 3 (week 24).

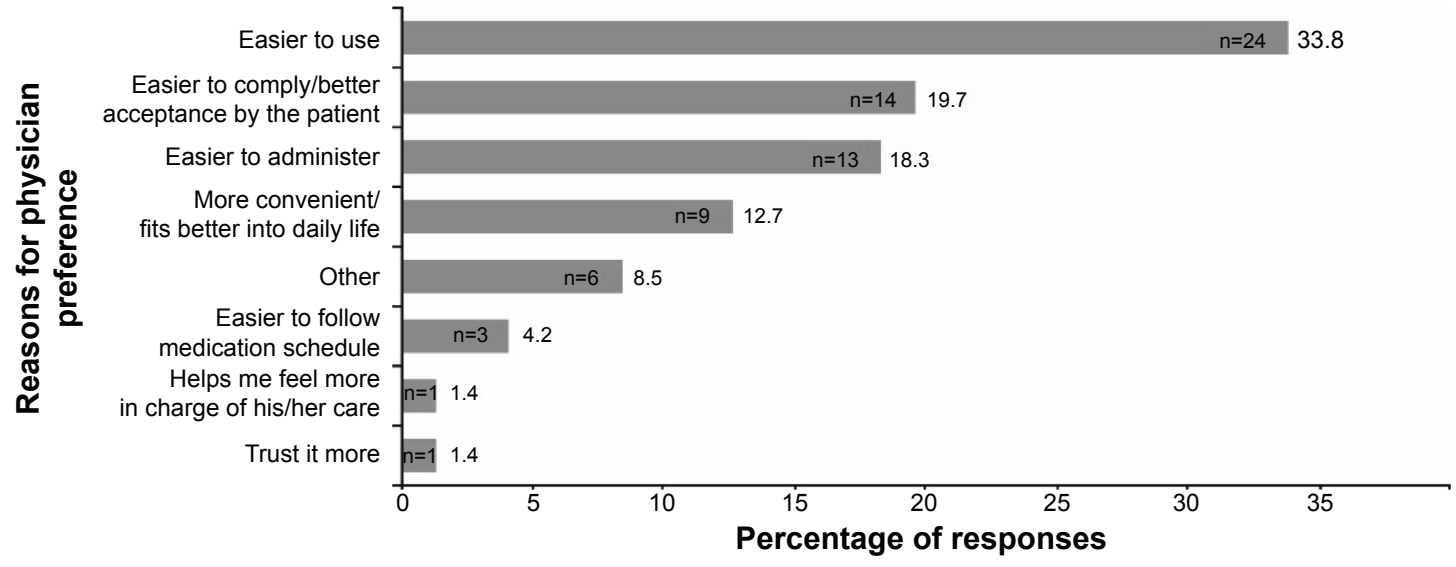

Figure 4 First ranking reason for physician preference for patch medication at the end of the study.

Notes: Of the 89 physicians, 71 indicated preference for transdermal compared with 18 for oral monotherapy at the end of the study. Information was collected only once for each physician.

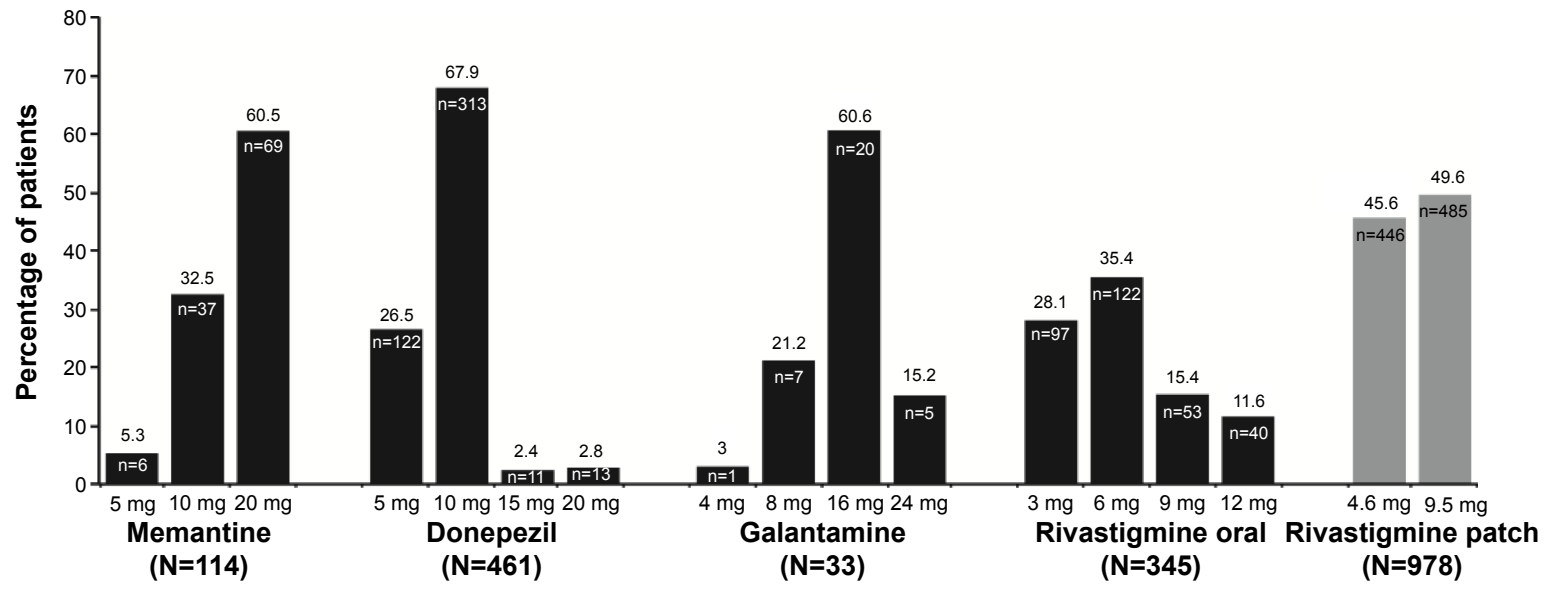

Figure 5 Drug regimen among patients on cholinesterase inhibitors and memantine at the end of the study. Notes: For patients who switched therapy during the study, the last monotherapy dosing has been used. 
scores at the end of the study were 18.6 (4.53) and 19.1 (4.57) in the oral and transdermal monotherapy cohorts, respectively. At the end of the study, the mean (SD) MMSE score increased by 0.5 (3.21) in the oral monotherapy cohort and by 1.4 (3.27) in the transdermal monotherapy cohort.

\section{Safety}

A total of 341 (17.7\%) patients reported AEs, with a comparable proportion in the two treatment cohorts (oral monotherapy: $163[17.1 \%]$ and transdermal monotherapy: $178[18.2 \%])$. The number of patients with pruritus and rash was higher in the transdermal monotherapy cohort (30 [3.1\%] and $22[2.2 \%]$, respectively) than in the oral monotherapy cohort (2 $[0.2 \%]$ and $1[0.1 \%]$, respectively), whereas the number of patients with nausea and vomiting was higher in the oral monotherapy cohort (22 [2.3\%] and $16[1.7 \%]$, respectively) than in the transdermal monotherapy cohort (8 [0.8\%] and $2[0.2 \%]$, respectively). Of the 1,931 patients enrolled in the study, 73 (3.8\%) discontinued prematurely from the study because of AEs (oral: 30 [3.1\%]; transdermal: 43 [4.4\%]). The most common AEs leading to discontinuation were rash (oral: 0 [0\%]; transdermal: 16 [1.6\%]), pruritus (oral: $0[0 \%]$; transdermal: 15 [1.5\%]), vomiting (oral: 13 [1.4\%]; transdermal: 1 [0.1\%]), nausea (oral: 5 [0.5\%]; transdermal: $0[0 \%]$ ), and decreased appetite (oral: $4[0.4 \%]$; transdermal: $0[0 \%])$. There was a higher incidence of nonserious AEs leading to discontinuation in the transdermal than in the oral monotherapy cohort (41 [4.2\%] for transdermal and 27 [2.8\%] for oral). The number of patients with serious AEs was slightly higher in the oral monotherapy cohort (40 [4.2\%] for oral and 31 [3.2\%] for transdermal). Of the $11(0.6 \%)$ deaths during the study, $5(0.5 \%)$ were from the oral monotherapy cohort and $6(0.6 \%)$ were from the transdermal monotherapy cohort; none were related to the study medications as assessed by the investigators.

\section{Discussion}

$\mathrm{AD}$ is the most common type of dementia where compliance with oral therapies is an issue. ${ }^{5}$ About half of the patients have been reported to have discontinued the use of cholinesterase inhibitors within 6-12 months. ${ }^{26-28}$ More than $74 \%$ of patients need assistance from their caregivers for medication management; ${ }^{28,29}$ hence, caregivers play a key role in the treatment selection and compliance. The management and administration of $\mathrm{AD}$ medications contribute to caregiver burden. ${ }^{5,30}$ Simplifying the treatment regimens and using alternative modes of administration may help to reduce the caregiver burden, which, in turn, may result in improved treatment compliance and have a positive impact on the patient's condition. ${ }^{5}$

RECAP was a 24-week, multicenter, prospective, noninterventional study that showed that the majority $(82.7 \%)$ of caregivers preferred rivastigmine transdermal monotherapy over oral monotherapy in patients who were exposed to both the modes of administration. Similarly, most physicians $(79.8 \%)$ indicated preference for the transdermal route and cited ease of use, ease of administration, and ease of compliance as the most important reasons for preference. Caregivers' preference for treatment of AD has been previously assessed in various other studies. IDEAL, the first pivotal trial that demonstrated efficacy of the transdermal patch rivastigmine, ${ }^{11,13}$ also showed higher caregivers' preference $(72 \%)$ for the transdermal monotherapy compared with the oral monotherapy. ${ }^{19}$ Similarly, the EMBRACE (Effective Management of Alzheimer's disease By tReating pAtients and relieving Caregivers with Exelon patch) study, which assessed the real-life effectiveness and tolerability of rivastigmine patch, showed high caregivers' preference (88.2\%) for the patch over oral medication in patients with mild-to-moderate $\mathrm{AD} .{ }^{15}$ Moreover, results from a recent observational study in patients with mild-to-moderate $\mathrm{AD}$ have reported that the transdermal formulation of rivastigmine reduces caregiver burden in daily practice. ${ }^{31} \mathrm{Com}-$ pared with these studies, the RECAP study was unique in geographical scope and was conducted in countries where patients with $\mathrm{AD}$ are reported to live predominantly in households with extended families. ${ }^{32}$ It could be expected that there would be lower caregiver burden with the traditional arrangement of family care; however, the difference in caregiver burden because of extended families has been reported to be negligible. ${ }^{32}$

The treatment noncompliance in chronic progressive disorders is known to result in poor disease control, rapid disease progression, and increased economic burden. ${ }^{33,34}$ Perceived lack of effectiveness, side effects, forgetfulness, and the burden of complex drug regimens are the most common reasons for low compliance in AD. ${ }^{5,30}$ The use of cholinesterase inhibitors is associated with a decreased risk of rapid cognitive deterioration, institutionalization, and increased patient's and caregiver's quality of life..$^{35-38}$ In the present study, the overall patient compliance for the transdermal patch was significantly greater than that for oral monotherapy. These results were consistent with the findings from the AXEPT (Alzheimer disease: eXamination of patiEnt comPliance and caregiver satisfacTion) study where compliance and satisfaction reported by caregivers 
were significantly higher with the transdermal rivastigmine patch than with the oral medications. ${ }^{14}$ Hence, the present study substantiated that the once-daily rivastigmine patch offers a user-friendly treatment alternative to achieve higher treatment compliance in patients with mild-tomoderate AD.

It is recommended to escalate the dose of cholinesterase inhibitors to the highest tolerated dose within the approved dose range for better outcomes. ${ }^{3}$ The higher cholinesterase inhibitor doses were associated with better cognitive and functional longitudinal outcomes, ${ }^{39}$ less home help services use ${ }^{40}$ delayed nursing home placement, ${ }^{41}$ and prolonged life expectancy. ${ }^{42}$ There results indicate that there is a need for optimizing the dose of cholinesterase inhibitors for the individual patients with AD. In the present study, a higher percentage of patients were able to reach a higher daily dose with the transdermal monotherapy compared with the oral cholinesterase inhibitor monotherapies, owing to lower gastrointestinal AEs with the transdermal patch. Transdermal administration provides a continuous delivery of rivastigmine through the skin into the bloodstream, avoiding first pass metabolism and allowing a better dose escalation strategy to improve the treatment outcomes. ${ }^{43}$ Despite the higher incidence of rash and pruritus in the transdermal group during the present study, caregivers preferred the transdermal route. Several other studies have also shown that the transdermal delivery of rivastigmine allows more patients to reach and maintain the therapeutic dose, offering additional therapeutic benefits as well as contributing to improved treatment compliance. . $^{19,43,44}$

The limitations of the current study were the nonrandomized methodology and the possibility of bias due to the inherent nature of observational, open-label research. The strength of this study was that it was conducted under "real-world" medical practice conditions, and there were a large number of patients from Asia and the Middle East where published data are limited in the literature until now and therefore the data coming from this study is important.

\section{Conclusion}

Our study showed higher caregiver and physician preference and greater patient compliance with the transdermal monotherapy in daily practice in an ethnically diverse population of patients with mild-to-moderate AD from Asia and the Middle East. Overall, the results provided evidence that the once-daily rivastigmine patch offers a user-friendly treatment alternative to achieve higher patient compliance and dose escalation for better outcomes.

\section{Acknowledgments}

The authors thank Keyur Brahmbhatt and K Ananda Krishna (both from Novartis Healthcare Pvt Ltd, Hyderabad, India), for their medical writing assistance and subsequent revisions based on authors' feedback. The authors thank Sashka Hristoskova, and Arthur Backer (both from Novartis Pharma AG, Basel, Switzerland), for their help in reviewing the manuscript. The authors also thank all the clinical investigators and study coordinators at the participating centers and all the patients who participated in the study.

\section{Author contributions}

$\mathrm{S}$ diTommaso and $\mathrm{O}$ Yuksel were involved in the concept and design of the study. All authors were involved in data collection, analysis, and/or interpretation of the results, as well as critical revision, and approval of the article.

\section{Disclosure}

This study was funded by Novartis Pharma AG and its respective affiliates. MC Pai, H Aref, N Bassil, N Kandiah, $\mathrm{JH}$ Lee, and AV Srinivasan received investigator fees related to the conduct of this study. MC Pai has received honorarium and CME sponsorship from Novartis and Eisai. $\mathrm{N}$ Kandiah has received honorarium and CME sponsorship from Lundbeck, Novartis, Eisai, and Medichem; he has also received research funding from SingHealth Foundation, Media Development Authority of Singapore, National Medical Research Council of Singapore, and Biomedical Research Council of Singapore. S diTommaso and O Yuksel are employees of Novartis and as such may be eligible for Novartis stock and stock options. The authors report no other conflicts of interest in this work.

\section{References}

1. Qiu C, Kivipelto M, von Strauss E. Epidemiology of Alzheimer's disease: occurrence, determinants, and strategies toward intervention. Dialogues Clin Neurosci. 2009;11(2):111-128.

2. Prince M, Prina M, Guerchet M, editors. Journey of caring: an analysis of long-term care for dementia. In: World Alzheimer Report 2013. London, UK: Alzheimer's Disease International; 2013:92.

3. Small G, Bullock R. Defining optimal treatment with cholinesterase inhibitors in Alzheimer's disease. Alzheimers Dement. 2011;7(2): 177-184.

4. Zarowitz BJ, Stefanacci R, Hollenack K, O’Shea T, Gruber J, Tangalos EG. The application of evidence-based principles of care in older persons (issue 5): Alzheimer's disease. J Am Med Dir Assoc. 2007;8(3): 183-193.

5. Small G, Dubois B. A review of compliance to treatment in Alzheimer's disease: potential benefits of a transdermal patch. Curr Med Res Opin. 2007;23(11):2705-2713

6. Haberstroh J, Hampel H, Pantel J. Optimal management of Alzheimer's disease patients: clinical guidelines and family advice. Neuropsychiatr Dis Treat. 2010;6:243-253. 
7. Cummings J, Winblad B. A rivastigmine patch for the treatment of Alzheimer's disease and Parkinson's disease dementia. Expert Rev Neurother. 2007;7(11):1457-1463.

8. Cummings J, Lefèvre G, Small G, Appel-Dingemanse S. Pharmacokinetic rationale for the rivastigmine patch. Neurology. 2007;69(4 Suppl 1): S10-S13.

9. Kurz A, Farlow M, Lefèvre G. Pharmacokinetics of a novel transdermal rivastigmine patch for the treatment of Alzheimer's disease: a review. Int J Clin Pract. 2009;63(5):799-805.

10. Farlow MR, Grossberg GT, Sadowsky CH, Meng X, Somogyi M. A 24-week, randomized, controlled trial of rivastigmine patch $13.3 \mathrm{mg}$ / $24 \mathrm{~h}$ versus $4.6 \mathrm{mg} / 24 \mathrm{~h}$ in severe Alzheimer's dementia. CNS Neurosci Ther. 2013;19(10):745-752.

11. Winblad B, Grossberg G, Frölich L, et al. IDEAL: a 6-month, doubleblind, placebo-controlled study of the first skin patch for Alzheimer disease. Neurology. 2007;69(4 Suppl 1):S14-S22.

12. Cummings J, Froelich L, Black SE, et al. Randomized, double-blind, parallel-group, 48-week study for efficacy and safety of a higher-dose rivastigmine patch (15 vs $\left.10 \mathrm{~cm}^{2}\right)$ in Alzheimer's disease. Dement Geriatr Cogn Disord. 2012;33(5):341-353.

13. Winblad B, Cummings J, Andreasen N, et al. A six-month doubleblind, randomized, placebo-controlled study of a transdermal patch in Alzheimer's disease - rivastigmine patch versus capsule. Int J Geriatr Psychiatry. 2007;22(5):456-467.

14. Bernabei R, Rossini PM, Di Cioccio L, et al. Compliance and caregiver satisfaction in Alzheimer's disease: results from the AXEPT Study. Dement Geriatr Cogn Dis Extra. 2012;2(1):418-432.

15. Gauthier S, Robillard A, Cohen S, et al; EMBRACE investigators. Reallife effectiveness and tolerability of the rivastigmine transdermal patch in patients with mild-to-moderate Alzheimer's disease: the EMBRACE study. Curr Med Res Opin. 2013;29(8):989-1000.

16. Cruz Jentoft AJ, Hernández B. Manejo terapéutico con rivastigmina en pacientes con enfermedad de Alzheimer de leve a moderadamente grave en condiciones de práctica clínica habitual. Estudio ENTERPRISE [Rivastigmine as treatment for patients with mild to moderately severe Alzheimer disease under normal clinical practice conditions. The ENTERPRISE study]. Neurologia. 2014;29(1):1-10. Spanish.

17. Boada M, Arranz FJ. Transdermal is better than oral: observational research of the satisfaction of caregivers of patients with Alzheimer's disease treated with rivastigmine. Dement Geriatr Cogn Disord. 2013; 35(1-2):23-33.

18. Directive 2001/20/EC of the European Parliament and of the Council of 4 April 2001 on the approximation of the laws, regulations and administrative provisions of the member states relating to the implementation of good clinical practice in the conduct of clinical trials on medicinal products for human use. Med Etika Bioet. 2002;9(1-2):12-19.

19. Winblad B, Kawata AK, Beusterien KM, et al. Caregiver preference for rivastigmine patch relative to capsules for treatment of probable Alzheimer's disease. Int J Geriatr Psychiatry. 2007;22(5):485-491.

20. Abetz L, Rofail D, Mertzanis P, et al. Alzheimer's disease treatment: assessing caregiver preferences for mode of treatment delivery. $A d v$ Ther. 2009;26(6):627-644.

21. Epstein M; International Society of Pharmacoepidemiology. Guidelines for good pharmacoepidemiology practices (GPP). Pharmacoepidemiol Drug Saf. 2005;14(8):589-595.

22. von Elm E, Altman DG, Egger M, et al; STROBE Initiative. The Strengthening the Reporting of Observational Studies in Epidemiology (STROBE) statement: guidelines for reporting observational studies. Lancet. 2007;370(9596):1453-1457.

23. Andersen K, Launer LJ, Dewey ME, et al. Gender differences in the incidence of $\mathrm{AD}$ and vascular dementia: The EURODEM Studies. EURODEM Incidence Research Group. Neurology. 1999;53(9): 1992-1997.

24. Cankurtaran M, Yavuz BB, Cankurtaran ES, Halil M, Ulger Z, Ariogul S. Risk factors and type of dementia: vascular or Alzheimer? Arch Gerontol Geriatr. 2008;47(1):25-34.
25. Fernández Martínez M, Castro Flores J, Pérez de Las Heras S, Mandaluniz Lekumberri A, Gordejuela Menocal M, Zarranz Imirizaldu JJ. Risk factors for dementia in the epidemiological study of Munguialde County (Basque Country-Spain). BMC Neurol. 2008;8:39.

26. Pariente A, Pinet M, Moride Y, Merlière Y, Moore N, Fourrier-Réglat A Factors associated with persistence of cholinesterase inhibitor treatments in the elderly. Pharmacoepidemiol Drug Saf. 2010;19(7):680-686.

27. Massoud F, Dorais M, Charbonneau C, Lescrauwaet B, Boucher JM, LeLorier J. Drug utilization review of cholinesterase inhibitors in Quebec. Can J Neurol Sci. 2008;35(4):508-509.

28. Herrmann N, Binder C, Dalziel W, Smyth S, Camacho F. Persistence with cholinesterase inhibitor therapy for dementia: an observational administrative health database study. Drugs Aging. 2009; 26(5):403-407.

29. Alzheimer's Association and National Alliance for Caregiving. Families care: Alzheimer's caregiving in the United States 2004. Available from: www.alz.org/national/documents/report_familiescare.pdf. Accessed July 13, 2015.

30. Singh G, Thomas SK, Arcona S, Lingala V, Mithal A. Treatment persistency with rivastigmine and donepezil in a large state medicaid program. J Am Geriatr Soc. 2005;53(7):1269-1270.

31. Adler G, Mueller B, Articus K. The transdermal formulation of rivastigmine improves caregiver burden and treatment adherence of patients with Alzheimer's disease under daily practice conditions. Int J Clin Pract. 2014;68(4):465-470.

32. Prince $M ; 10 / 66$ Dementia Research Group. Care arrangements for people with dementia in developing countries. Int J Geriatr Psychiatry. 2004;19(2):170-177.

33. Osterberg L, Blaschke T. Adherence to medication. NEngl J Med. 2005; 353(5):487-497.

34. Hughes CM. Medication non-adherence in the elderly: how big is the problem? Drugs Aging. 2004;21(12):793-811.

35. Vellone E, Piras G, Talucci C, Cohen MZ. Quality of life for caregivers of people with Alzheimer's disease. J Adv Nurs. 2008;61(2):222-231.

36. Molinuevo JL, Hernandez B; Grupo de Trabajo del Estudio IMPACT. Perfil del cuidador informal asociado al manejo clínico del paciente con enfermedad de Alzheimer no respondedor al tratamiento sintomático de la enfermedad [Profile of the informal carer associated with the clinical management of the Alzheimer's disease patient refractory to symptomatic treatment of the disease]. Neurologia. 2011;26(9):518-527. Spanish.

37. Howe E. Improving the quality of life in patients with Alzheimer's disease. Psychiatry (Edgmont). 2008;5(8):51-56.

38. Gillette-Guyonnet S, Andrieu S, Cortes F, et al. Outcome of Alzheimer's disease: potential impact of cholinesterase inhibitors. J Gerontol A Biol Sci Med Sci. 2006;61(5):516-520.

39. Wattmo C, Wallin AK, Minthon L. Progression of mild Alzheimer's disease: knowledge and prediction models required for future treatment strategies. Alzheimers Res Ther. 2013;5(5):44.

40. Wattmo C, Paulsson E, Minthon L, Londos E. A longitudinal study of risk factors for community-based home help services in Alzheimer's disease: the influence of cholinesterase inhibitor therapy. Clin Interv Aging. 2013;8:329-339.

41. Wattmo C, Wallin AK, Londos E, Minthon L. Risk factors for nursing home placement in Alzheimer's disease: a longitudinal study of cognition, ADL, service utilization, and cholinesterase inhibitor treatment. Gerontologist. 2011;51(1):17-27.

42. Wattmo C, Londos E, Minthon L. Response to cholinesterase inhibitors affects lifespan in Alzheimer's disease. BMC Neurol. 2014;14:173.

43. Oertel W, Ross JS, Eggert K, Adler G. Rationale for transdermal drug administration in Alzheimer disease. Neurology. 2007;69(4 Suppl 1): S4-S9.

44. Articus K, Baier M, Tracik F, Kühn F, Preuss UW, Kurz A. A 24-week, multicentre, open evaluation of the clinical effectiveness of the rivastigmine patch in patients with probable Alzheimer's disease. Int J Clin Pract. 2011;65(7):790-796. 


\section{Publish your work in this journal}

Clinical Interventions in Aging is an international, peer-reviewed journal focusing on evidence-based reports on the value or lack thereof of treatments intended to prevent or delay the onset of maladaptive correlates of aging in human beings. This journal is indexed on PubMed Central, MedLine,

CAS, Scopus and the Elsevier Bibliographic databases. The manuscript management system is completely online and includes a very quick and fair peer-review system, which is all easy to use. Visit http://www.dovepress. com/testimonials.php to read real quotes from published authors.

Submit your manuscript here: http://www.dovepress.com/clinical-interventions-in-aging-journal 